\title{
The data show it: Size matters
}

\author{
David M. Overman, MD
}

From the Division of Cardiac Surgery, The Children's Heart Clinic, Minneapolis, Minn; and Division of
Cardiovascular Surgery, Children's Minnesota, Minneapolis, Minn.
Disclosures: Author has nothing to disclose with regard to commercial support.
Received for publication Nov 30, 2018; accepted for publication Dec 3, 2018.
Address for reprints: David M. Overman, MD, The Children's Heart Clinic, 2530 Chicago Ave South, Suite 500,
Minneapolis, MN 55404 (E-mail: doverman@ @hc-pa.org).
J Thorac Cardiovasc Surg 2019;157:1144-5
0022-5223/\$36.00
Copyright @ 2018 by The American Association for Thoracic Surgery
https://doi.org/10.1016/j.jtcvs.2018.12.012

"Science is a first rate piece of furniture for a man's upper chamber, if he has common sense on the ground floor."

\section{- Oliver Wendell Holmes, Sr}

In 1982, 14\% of drivers in the United States used a seat belt. In 2017, that figure reached $90 \% .{ }^{1}$ By extrapolating from existing data, approximately half a million traffic fatalities have been avoided by this increase in seat-belt use. Putting on a seat belt to be safe is such a simple and intuitive idea. But nothing convinces us of its efficacy more than the data.

As we all know, the story of the birth and development of cardiac surgery, the climax of which is the achievement of complex repairs in neonates, is one of the most compelling and impressive narratives of our time. As that story unfolded, the field pursued the logical extension of the principle that primary complete repair of congenital defects was not only achievable but also preferable to medical management or palliation. Single-center reports of the feasibility of complete repairs in low-birth-weight and premature infants pushed a sometimes reluctant surgical community to undertake operations regardless of age or size. ${ }^{2,3}$ It is widely acknowledged and agreed on that the foundational principle in play here is to avoid the morbidity and mortality associated with delaying an achievable repair. And there is, indeed, measurable morbidity and mortality incurred when definitive repair is delayed in the face of recognizable signs and symptoms (failure to thrive with left-to-right shunt physiology) or known pathophysiologic consequences (left ventricular deconditioning in transposition of the great arteries/intact ventricular septum). Nevertheless, feasibility and advisability are distinctly different concepts, and they should not be confused.

When does the strategy of early definitive repair begin to incur risk that outweighs the proposed benefit? This is, of course, a riddle we collectively revisit time and time again across many clinical scenarios. The mere fact that we revisit the question stands as testament to a lack of compelling evidence in a field where numbers are low, complexity is high, and the iterations of therapeutic strategies are innumerable. Single-center experiences are distinctly biased and can

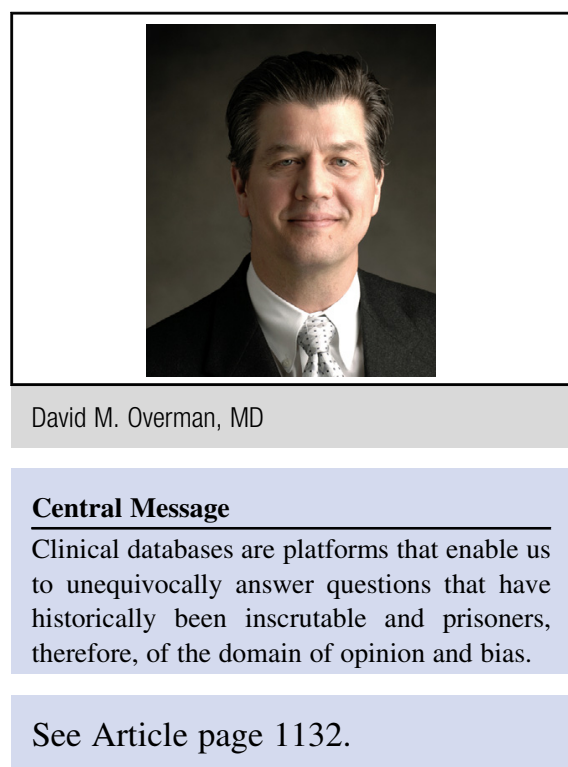

rarely serve as anything more than hints at what might be. It is a frustrating reality in a field where the importance of being right cannot be overstated.

Enter the era of congenital heart surgery databases. These databases, which mainly describe activity in North America, Europe, and Japan, now contain approximately 1 million surgical episodes, share a common nomenclature, and continually undergo data verification. We now have at our disposal reasonably granular and accurate data with enough statistical power to address these many questions. The data can finally speak.

In this analysis from the Congenital Section of the Japan Cardiovascular Surgery Database, Inohara and colleagues ${ }^{4}$ attempt to establish an "empiric threshold" of weight below which the occurrence of a composite end point of death or major complication begins to increase. The study cohort consists of approximately 5000 patients with a fundamental diagnosis of ventricular septal defect and who also underwent ventricular septal defect closure or pulmonary artery banding (or both) at less than 1 year of age. One notable aspect of this analysis is that although overall operative mortality was, as expected, very low $(0.5 \%$, nearly identical to outcomes reported for the Society of Thoracic Surgeons Congenital Heart Surgery Database Harvest Report ${ }^{5}$ ), the incidence of the composite end point was, in fact, nontrivial $(5.8 \%)$. The central finding is illustrated in Figures 2 and $3,{ }^{4}$ which elegantly demonstrate the sharply increasing risk of the composite outcome below a weight of approximately $4.5 \mathrm{~kg}$. Below $3.0 \mathrm{~kg}$, the analysis projects a rate of $10 \%$ or more! It should also be noted that 
mortality risk, although still very low, was significantly elevated below the "empiric threshold" as well $(0.2 \%$ vs $0.7 \%, P=.007)$.

These findings are mirrored in other single-institution studies examining risk factors for prolonged length of stay or other measures of complicated recovery. ${ }^{6}$ But it takes the platform of a clinical database, a mere fantasy before the 21 st century, to have the power to unequivocally establish such associations in the statistically challenging setting of congenital heart surgery.

Will this analysis change clinical decision making or practice? Almost certainly not. Most surgeons would not undertake surgery for ventricular septal defects in the very young or the very small unless clinically compelled to do so. But that, in fact, is the point. Operate when compelled, of course, but let us not fall victim to the notion that being younger and smaller is without import. The analysis of Inohara and colleagues ${ }^{4}$ is a wonderful example of how our clinical databases should be used, and the power they have to dispel underpowered assertions or biases and definitively establish facts. The data speak for themselves, and, what do you know, they comport with common sense!

\section{References}

1. National Highway Traffic Safety Administration. Crash Stats. Washington, DC: DOT HS 812 546; June; 2018.

2. Chang AC, Hanley FL, Lock JE, Castaneda AR, Wessel DL. Management and outcome of low birth weight neonates with congenital heart disease. J Pediatr. 1994;124:461-6.

3. Reddy VM, Mcelhinney DB, Sagrado T, Parry AJ, Teitel DF, Hanley FL. Results of 102 cases of complete repair of congenital heart defects in patients weighing 700 to 2500 grams. J Thorac Cardiovasc Surg. 1999;117:324-31.

4. Inohara T, Ichihara N, Kohsaka S, Miyata H, Hirata Y, Murakami A, et al. The effect of body weight in infants undergoing ventricular septal defect closure: a report from nationwide Japanese congenital surgical database. J Thorac Cardiovasc Surg. 2019;157:1132-41

5. Jacobs JP, O'Brien SM, Jacobs ML, Lacour-Gayet FG, Tchervenkov CI, Austin EH III, et al. Variation in outcomes for benchmark operations: an analysis of the STS congenital heart surgery database. Ann Thor Surg. 2011;92:2184-92.

6. Schipper M, Slieker MG, Shoof PH, Breur JMPJ. Surgical repair of ventricular septal defect; contemporary results and risk factors for a complicated course. $\mathrm{Pe}$ diatr Cardiol. 2017;38:264-70.

7. Curzon CL, Milford-Beland S, Li JS, O’Brien SM, Jacobs JP, Jacobs ML, et al. Cardiac surgery in infants with low birth weight is associated with increased mortality: analysis of the Society of Thoracic Surgeons congenital heart database. J Thorac Cardiovasc Surg. 2008;135:546-51. 